\title{
Sudden Unexpected Death in Epilepsy Counseling-An American Epilepsy Society Position Statement
}

\author{
An Expert Interview with William D Gaillard
}

Division of Child Neurology, Epilepsy, and Neurophysiology, Children's National Medical Center, George Washington University School of Medicine and Health Sciences, Washington, DC, USA

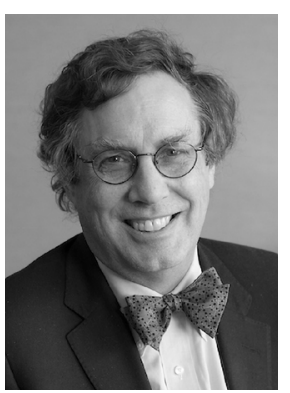

\begin{abstract}
William D Gaillard
William Davis Gaillard is the current president of the American Epilepsy Society, is Professor of Pediatrics and Neurology at George Washington University, and Chief of Neurology at the Children's National Hospital, where he is also director of the Comprehensive Pediatric Epilepsy Program, one of the leading multidisciplinary pediatric epilepsy programs in the country. He earned his MD degree from Yale University School of Medicine in 1985. He completed his pediatric training at Children's Hospital in Pittsburgh, his neurology training at Johns Hopkins, and an epilepsy, neurophysiology, and imaging fellowship at the National Institute of Neurological Disorders and Stroke. His research involves imaging the effects of childhood epilepsy on brain structure and function. He has also worked to use Electronic Health Record (EHR) systems to improve and standardize epilepsy care, and has surveyed access to care, and other aspects of clinical practice including patient education on mortality in epilepsy and sudden unexpected death in epilepsy. Professor Gaillard has been Treasurer of the American Epilepsy Society, Chair of the International League Against Epilepsy (ILAE) Commission on Diagnostics, Chair of the ILAE Pediatric Epilepsy Surgery Task Force, and member of the Pediatric Commission. He is an associate editor of Epilepsy Research and has been an associate editor of Epilepsia. He is the author of more than 200 peer-reviewed scientific papers and more than 50 chapters.
\end{abstract}

\section{Keywords}

Epilepsy, sudden death, sudden unexpected death in epilepsy, SUDEP

Disclosure: William D Gaillard has no financial or non-financial relationships or activities to declare in relation to this expert interview.

Acknowledgments: Medical writing assistance was provided by Katrina Mountfort of Touch Medical Media and was supported by Touch Medical Media.

Review Process: This is an expert interview and, as such, has not undergone the journal's standard peer review process.

Authorship: The named author meets the International Committee of Medical Journal Editors (ICMJE) criteria for authorship of this manuscript, takes responsibility for the integrity of the work as a whole, and has given final approval to the version to be published.

Access: This article is freely accessible at touchNEUROLOGY.com (c) Touch Medical Media 2020

Received: November 3, 2019

Published Online: January 8, 2020

Citation: US Neurology. 2020;16(1):13-4

Corresponding Author: William D Gaillard, Children's National Medical Center, 111 Michigan Ave NW, Washington, DC 20010, USA. E: wgaillar@childrensnational.org

Support: No funding was received in

the publication of this article.
$\mathrm{T}$ he majority of people with epilepsy develop lasting remission from seizures. However, epilepsy can be fatal; with sudden unexpected death in epilepsy (SUDEP) the most common epilepsy-related cause of death. ' SUDEP is defined as unexpected, witnessed or unwitnessed, non-traumatic, and non-drowning death that occurs in an individual with epilepsy with or without evidence for a seizure. ${ }^{2}$ Each year, around 1 in 1,000 adults with epilepsy are affected by SUDEP, and it is thought to be less common in children, though recent evidence suggests rates of SUDEP in children may be closer to those currently reported in adults. ${ }^{3-5}$ In some specific childhood epilepsy syndromes, such as Dravet syndrome, the incidence is much higher. ${ }^{6}$

The American Academy of Neurology (AAN)/American Epilepsy Society (AES) 2017 practice guideline summary encourages counseling for patients, families, and caregivers about the risk of SUDEP. ${ }^{3}$ The AES has recently released a position statement on SUDEP counseling. In an expert interview, Professor Gaillard explains the need for this statement and discusses the importance of SUDEP counseling.

\section{Q. Why was there a need for a new position statement relating to sudden unexpected death in epilepsy?}

The position statement is a statement of practice accelerated in response to the death of Disney star Cameron Boyce, which was extensively reported in the US press. This provided an opportunity to raise awareness of SUDEP and discuSS SUDEP counseling. Many people believe that epilepsy is a benign condition, but there has been increasing recognition that epilepsy is deadly. Extensive efforts have been made to understand why people die of epilepsy and to mitigate the risks. There have been a number of funded initiatives through Citizens United for Research in Epilepsy (CURE) and the National Institute of Neurological Disorders and Stroke (NINDS) to understand the mechanisms of SUDEP and at-risk individuals., ${ }^{, 9}$ Much of this research has been driven by Gardiner Lapham, who has worked through CURE and the NINDS for the funding of the Centers Without Walls initiative to understand SUDEP, as well as studies in animal models to understand mechanisms in at risk populations. ${ }^{10-12}$

\section{Q. What are the major features of the statement?}

This is a policy statement about the incidence of SUDEP, what is known about the risk factors for SUDEP, and what physicians should be considering when they speak to families about the risk of SUDEP. 
Many physicians, including skilled epileptologists, often do not talk to families about SUDEP. ${ }^{13}$ There are a variety of reasons for this, including limited time in clinic visits, a sense of other issues prioritized as needing to be covered, and a sense that there is little that one can do. However, it is important to stress the importance of compliance to medicine, aggressively treating seizures, and characteristics by which high-risk patients might be identified. It is clear that families want to hear about the risk of death at their first meeting with their physician, as this is their greatest fear. 14,15 They do not want to wait until later in their treatment to have that discussion. I have found that almost everyone I see has already looked up the risk of death on the internet, so if I don't talk to patients and families about risk of death, I am not fulfilling my obligations as a physician to provide information. The information can be reassuring, especially for children and individuals who are at lower risk. It is also important to recognize those who are at higher risk, even though current ways of minimizing those risks are crude at the moment, but the information may emerge in the future. The statement discusses the need for the conversation about SUDEP, how the conversation might happen, and then summarizes the evidence for risk and the importance of continued research.

\section{Q. In what scenarios should SUDEP counseling be considered?}

SUDEP should be discussed at the first visit for new onset epilepsy evaluation. It is important for individuals at higher risk, but can also be reassuring for the families of individuals at lower risk. Risk factors include generalized tonic clonic ("convulsive") seizures, Dravet syndrome, seizures during sleep, and nonadherence to treatment.6,16 It is important to address early the anxiety caused by the thought that a child is going to die. ${ }^{6}$

\section{Q. What is the recommended approach to SUDEP counseling?}

We do not dictate how counseling should be done; we provide the framework in which this practice might occur. The extent of counseling should be individually tailored to each patient and family member according to the specific epilepsy type, patient preference, caregiver availability and/or engagement, and living environment.

\section{Q. What SUDEP-related resources are available for patients with epilepsy and their caregivers?}

The AAN/AES provide content in terms of counseling method, as well as many online sources, such as The Epilepsy Foundation of America, who have an educational page about SUDEP, ${ }_{17}$ and the Centers for Disease Control and Prevention. ${ }^{18}$ Two other useful resources are the Danny Did ${ }^{\circledR}$ Foundation ${ }^{19}$ and the Partners Against Mortality in Epilepsy organization, ${ }^{20}$ which brings healthcare professionals together with public health officials and people who have epilepsy and their families/caregivers. $]$
1. Lhatoo $S D$, Langan $Y$, Sander JW. Sudden unexpected death in epilepsy. Postgrad Med J. 1999;75:706-9.

2. Nashef L, So EL, Ryvlin P, et al. Unifying the definitions of sudden unexpected death in epilepsy. Epilepsia. 2012;53:227-33.

3. Harden C, Tomson T, Gloss D, et al. Practice guideline summary. Sudden unexpected death in epilepsy incidence rates and risk factors. Report of the Guideline Development, Dissemination, and Implementation Subcommittee of the American Academy of Neurology and the American Epilepsy Society. Neurology. 2017;88:1674-80.

4. Keller AE, Whitney R, Li SA, et al. Incidence of sudden unexpected death in epilepsy in children is similar to adults. Neurology. 2018;91:e107-11

5. Sveinsson $\mathrm{O}$, Andersson $\mathrm{T}$, Carlsson $\mathrm{S}$, et al. The incidence of SUDEP: a nationwide population-based cohort study. Neurology. 2017;89:170-7.

6. Shmuely S, Sisodiya SM, Gunning WB, et al. Mortality in Dravet syndrome: a review. Epilepsy Behav. 2016;64:69-74.

7. American Epilepsy Society (AES). AES position statement on SUDEP counseling. 2019. Available at: www.aesnet.org/sites/ default/files/file_attach/2019-10-22-AES_SUDEP_Position_ Statement.pdf (accessed November 5, 2019).
8. Citizens United for Research in Epilepsy (CURE). About CURE'S SUDEP program. Available at: www.cureepilepsy.org/signature programs/sudden-unexpected-death-in-epilepsy/ (accessed January 3,2020 ).

9. National Institute of Neurological Disorders and Stroke (NINDS). NINDS launches new epilepsy centers without walls. 2014 Available at: www.ninds.nih.gov/News-Events/DirectorsAvallable at: Www.ninds.nih.gov/News-Events/Directors-
Messages/All-Directors-Messages/NINDS-Launches-New Epilepsy-Center-Without (accessed January 3, 2020)

10. Lapham G, Gaillard WD, Sexter J, Berl MM. Increasing awareness of sudden death in pediatric epilepsy together. Pediatrics. 2017; 139:e20163127.

11. Lhatoo SD, Nei M, Raghavan $M$, et al. Nonseizure SUDEP: sudden unexpected death in epilepsy without preceding epileptic seizures. Epilepsia. 2016:57:1161-8.

12. Lhatoo S, Noebels J, Whittemore V; NINDS Center for SUDEP Research. Sudden unexpected death in epilepsy: identifying risk and preventing mortality. Epilepsia. 2015;56:1700-6.

13. Friedman D, Donner EJ, Stephens D, et al. Sudden unexpected death in epilepsy: knowledge and experience among U.S. and Canadian neurologists. Epilepsy Behav. 2014;35:13-8.

14. Gayatri NA, Morrall MC, Jain V, et al. Parental and physician beliefs regarding the provision and content of written sudden unexpected death in epilepsy (SUDEP) information. Epilepsia. 2010;51:777-82

15. RamachandranNair R, Jack SM. SUDEP: what do adult patients want to know? Epilepsy Behav. 2016;64:195-9.

16. Devinsky O, Hesdorffer DC, Thurman DJ, et al. Sudden unexpected death in epilepsy: epidemiology, mechanisms, and prevention. Lancet Neurol. 2016;15:1075-88.

17. Epilepsy Foundation. SUDEP. 2013. Available at: www.epilepsy.com/learn/early-death-and-sudep/sudep (accessed November 5, 2019).

18. Centers for Disease Control and Prevention (CDC). Sudden unexpected death in epilepsy (SUDEP). 2018. Available at: www.cdc.gov/epilepsy/about/sudep/index.htm (accessed November 5, 2019)

19. Danny Did ${ }^{\otimes}$ Foundation. Advancing awareness of epilepsy and sudden unexpected death in epilepsy (SUDEP). Available at: www.dannydid.org/ (accessed November 5, 2019).

20. Partners Against Mortality in Epilepsy (PAME). Available at: https://pame.aesnet.org/ (accessed November 5, 2019). 